Research Article

\title{
Flow Field Simulation and Noise Control of a Twin-Screw Engine-Driven Supercharger
}

\author{
Tao Wang, ${ }^{1}$ Bo Li, ${ }^{1}$ QiangQiang Peng, ${ }^{2}$ ZhiLong He, ${ }^{1}$ and XueYuan Peng ${ }^{1}$ \\ ${ }^{1}$ School of Energy and Power Engineering, Xi'an Jiaotong University, Xian 710049, China \\ ${ }^{2}$ Gree Electric Appliances Inc. of Zhuhai, Zhuhai 519070, China \\ Correspondence should be addressed to ZhiLong He; zlhe@mail.xjtu.edu.cn
}

Received 20 November 2015; Accepted 6 March 2016

Academic Editor: Sergey A. Suslov

Copyright (c) 2016 Tao Wang et al. This is an open access article distributed under the Creative Commons Attribution License, which permits unrestricted use, distribution, and reproduction in any medium, provided the original work is properly cited.

\begin{abstract}
With the advantages of good low-speed torque capability and excellent instant response performance, twin-screw superchargers have great potential in the automobile market, but the noise of these superchargers is the main factor that discourages their use. Therefore, it is important to study their noise mechanism and methods of reducing it. This study included a transient numerical simulation of a twin-screw supercharger flow field with computational fluid dynamics software and an analysis of the pressure field of the running rotor. The results showed that overcompression was significant in the compression end stage of the supercharger, resulting in a surge in airflow to a supersonic speed and the production of shock waves that resulted in loud noise. On the basis of these findings, optimization of the supercharger is proposed, including expansion of the supercharger exhaust orifice and creation of a slot along the direction of the rotor spiral normal line at the exhaust port, so as to reduce the compression end pressure, improve the exhaust flow channel, and weaken the source of the noise. Experimental results showed that the noise level value of the improved twin-screw supercharger was significantly lower at the same speed than the original model, with an average decrease of about $5 \mathrm{~dB}$ (A).
\end{abstract}

\section{Introduction}

In the decades before the 21st century, turbo supercharging technology played a large role in the market. However, due to the slow speeds of vehicles in modern cities, long periods spent idling, and frequently alternating engine conditions, the requirements for engines have changed, and their lowspeed torque characteristics and transient response capability have become common concerns. Because of the simultaneous rapid development of design and manufacturing standards, increased requirements of users for engine power and efficiency, and international emission regulations, engine-driven supercharging technology has again captured the automotive industry's attention.

The screw supercharger is a typical application of the screw compressor, in which the difference between the exhaust ports (gas pressure within the element volume within the compression pressure) and the external pressure (exhaust pipes of gas pressure) causes the element volume and the exhaust hole to communicate, with instantaneous, constant volume gas expansion or compression. Communication of this periodic discharge pressure pulsation in the flow loss increases, which leads to additional energy loss. The gas pulsation in the exhaust pipes always achieves the noise of compressor and the power consumed by the compressor greatly increasing. Therefore, it is important to study the flow characteristics of the exhaust process of screw compressors. Koai et al. studied the twin-screw compressor airflow ripple according to the geometric parameters of screw compressor effect analysis of the periodic excitation source and different load of pressure fluctuation; at the same time, they performed four-end parameter analysis of exhaust gas pulsation of the piping system $[1,2]$. Wu et al. performed a theoretical and experimental study of the screw compressor exhaust airflow ripple considering the effects of condition and speed on discharge pressure pulsation [3]. Huang et al. studied gas pulsation and proposed the pulsation trap method to reduce compressor airflow ripple and noise [4]. Mujic et al. proposed that the discharge port was an important parameter influencing the gas pulsations and the gas pulsations amplitude can 
be reduced by optimization of the port shape [5]. Mahendra and Olsen analyzed the unsteady velocity field at the outlet of three-lobe supercharger using particle image velocimetry (PIV) and showed that the flow exits the supercharger as a high-speed jet that varies not only in the parallel plane but also in the perpendicular plane, generating a complex three-dimensional flow [6]. However, there is little research or information on the gas pulsation and noise of screw superchargers. With the development of computer technology, the application of computational fluid dynamics (CFD) technology provides a powerful tool to analyze the flow field of the screw compressor and to obtain the function of the excitation source [7-11]. Kovacevic et al. described some aspects of an advanced grid generation method used, with CFD procedures, to model three-dimensional flow through screw compressors [12], and how CFD is merged with other design software by means of an integral management system to obtain interactive control of the entire design process of screw compressors [13]. Huang and Liu visually analyzed the evolutionary characteristics of flow for the positive displacement blower by performing numerical simulation of unsteady compressible flow in a three-lobe positive discharge blower using computational fluid dynamics and showed that the differences of result between the simulation $s$ and the semiempirical method were due to pressure fluctuations and the existence of a vortex in the mixing zone [14].

Compared with traditional turbochargers, twin-screw engine-driven superchargers have great market potential because of their better low-speed torque characteristics, good transient response capability, and lower exhaust pressure [15]. However, the noise of these superchargers is the main factor that discourages their use. Therefore, it is important to study their noise mechanism and methods of reducing it. The noise problem of twin-screw superchargers has affected their use and promotion, so research into twin-screw superchargers' noise mechanism and their optimization has important applications.

In this paper, the mathematical model and calculation method of the screw supercharger are established, and the flow characteristics of the exhaust process of the screw supercharger are simulated. The optimization scheme of the supercharger is presented, and the theoretical basis is provided for the optimization design of the structure and the vibration and noise reduction.

\section{Numerical Simulation and Optimization}

The fluid flow in a screw supercharger must follow the law of physical conservation, which basically includes the law of mass conservation, the law of momentum conservation, and the law of energy conservation. The governing equations describe these conservation laws in mathematics.

(1) Mass Conservation Equation. Consider

$$
\frac{\partial \rho}{\partial t}+\frac{\partial(\rho u)}{\partial x}+\frac{\partial(\rho v)}{\partial y}+\frac{\partial(\rho w)}{\partial z}=0 .
$$

(2) Momentum Conservation Equation. Consider

$$
\begin{aligned}
\frac{\partial(\rho u)}{\partial t}+\operatorname{div}(\rho u u)= & -\frac{\partial p}{\partial x}+\frac{\partial \tau_{x x}}{\partial x}+\frac{\partial \tau_{y x}}{\partial y}+\frac{\partial \tau_{z x}}{\partial z} \\
& +F_{x}, \\
\frac{\partial(\rho v)}{\partial t}+\operatorname{div}(\rho v u)= & -\frac{\partial p}{\partial y}+\frac{\partial \tau_{x y}}{\partial x}+\frac{\partial \tau_{y y}}{\partial y}+\frac{\partial \tau_{z y}}{\partial z} \\
& +F_{y}, \\
\frac{\partial(\rho w)}{\partial t}+\operatorname{div}(\rho w u)= & -\frac{\partial p}{\partial z}+\frac{\partial \tau_{x z}}{\partial x}+\frac{\partial \tau_{y z}}{\partial y}+\frac{\partial \tau_{z z}}{\partial z} \\
& +F_{z} .
\end{aligned}
$$

(3) Energy Conservation Equation. Consider

$$
\frac{\partial(\rho t)}{\partial t}+\operatorname{div}(\rho u t)=\operatorname{div}\left(\frac{k}{c_{p}} \operatorname{grad} t\right)+S_{T} .
$$

According to the model's characteristics, the large eddy simulation approach is applied in this paper. The basic assumptions of the large eddy simulation method are as follows [16]:

(1) Various types of scalar in the flow field are transported by large eddy.

(2) The characteristics of the flow field shown by the large eddy model and the characteristics of a large eddy are determined by the geometry and boundary conditions of the flow field.

(3) The small eddy is less affected by the geometry and boundary conditions and is regarded as isotropic.

On this basis, this paper includes a transient numerical simulation of a twin-screw supercharger. The basic structure is as shown in Figure 1.

Figure 2 shows the meshing of the shell chamber. Figures 3 and 4 the meshing of the female and male rotors, respectively.

Before optimization, the pressure field in original model was analyzed, the pressure distribution of the central cross section of the female and male rotors was specifically examined, and the flow fields were analyzed at three different moments. The position of the central section is shown in Figure 5, and the three moments correspond to the three positions of the rotor during the compression process, at the compression end stage, and after the exhaust stage.

The central cross section pressure distributions of the twin-screw engine-driven supercharger's different rotor positions are shown in Figures 6(a), 6(b), and 6(c), respectively.

Figure 6 shows that the pressure in the compression chamber increased gradually during the rotating compression process of the rotor. It reached its maximum at the compression end stage, at about $0.16 \mathrm{MPa}$ or more, after the rotor entered the exhaust position, and the chamber pressure quickly dropped to a value in line with the back pressure. 

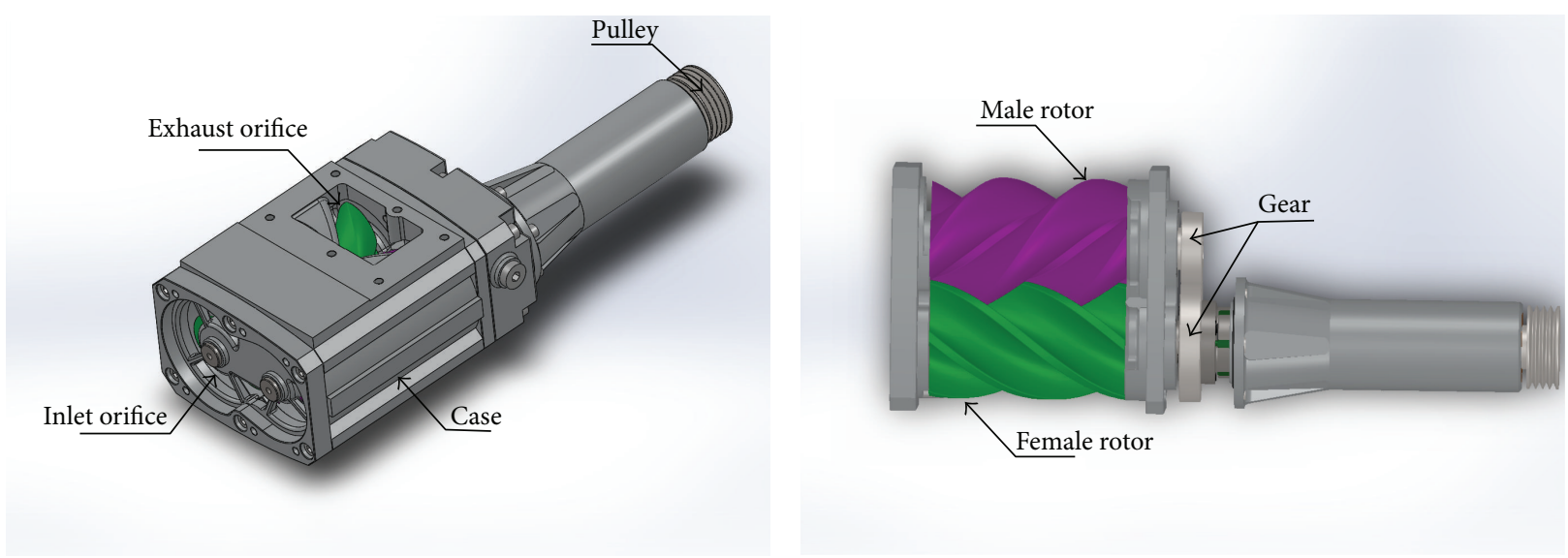

FIGURE 1: Overall view and internal view of a twin-screw supercharger.

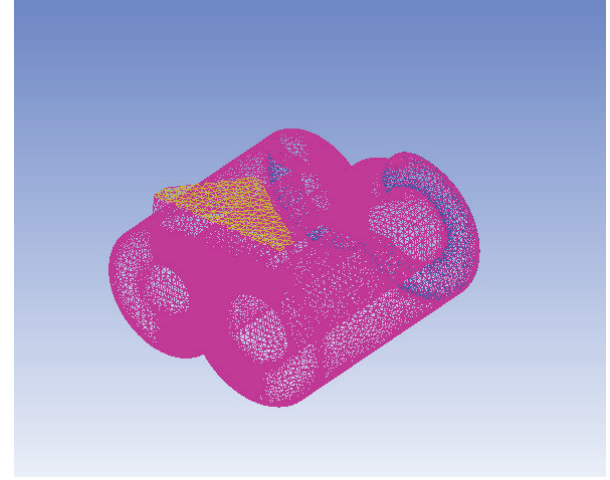

FIGURE 2: Mesh of a twin-screw engine-driven supercharger shell chamber.

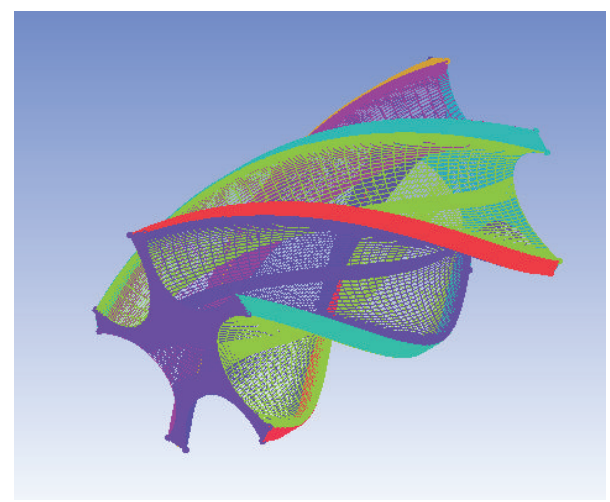

FIGURE 3: Female rotor meshes.

Because the maximum pressure of $0.16 \mathrm{MPa}$ or more was much higher than the back pressure of $0.1349 \mathrm{MPa}$, it was in an overcompressed state, which not only produced severe noise but also wasted the energy required by the compression process; therefore, it is necessary to take measures to reduce the compression end pressure. Based on the analysis of the original model flow field, a program has been proposed to lower the compression end pressure, that is, to expand

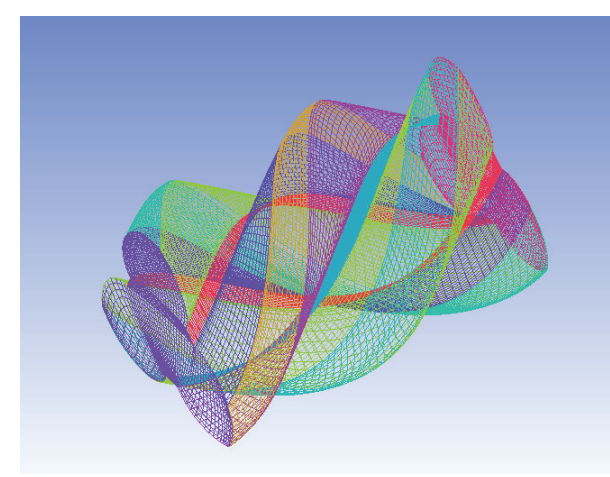

Figure 4: Male rotor meshes.

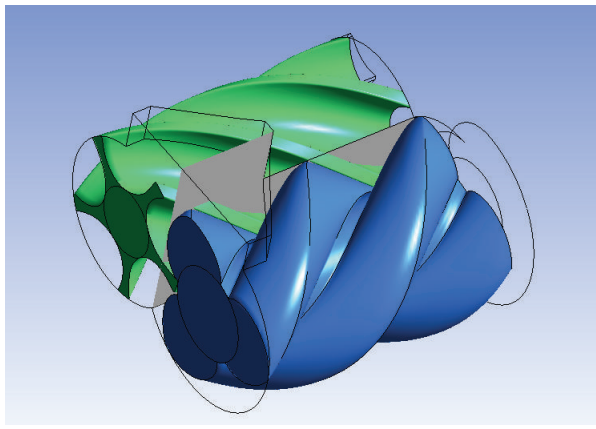

Figure 5: Center section position.

the exhaust orifice and create a slot along the direction of the rotor spiral normal line on the exhaust orifice.

To verify the new scheme, the pressure distributions in the central section at five different moments were selected for analysis of the changes in flow field pressure in the compression chamber. The five moments were (1) the moment before the rotor makes contact with the slot, (2) the moment at which the rotor begins to contact the slot, (3) the moment during which the rotor contacts the slot, (4) the end of the stage at which the rotor contacts the slot (i.e., when the rotor 


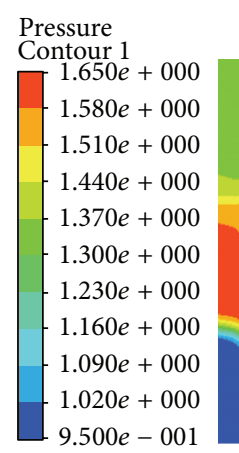
[Bar
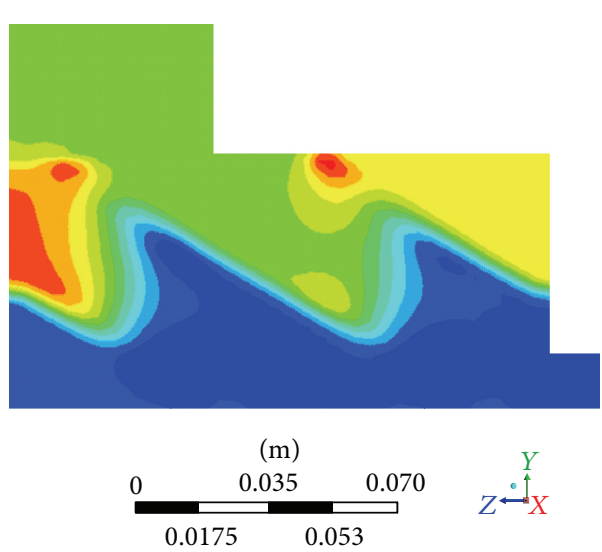

(a)

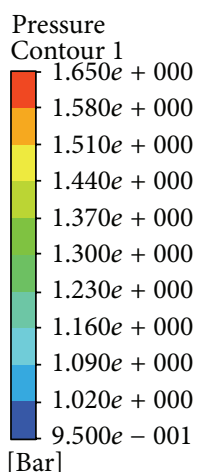

[Bar]
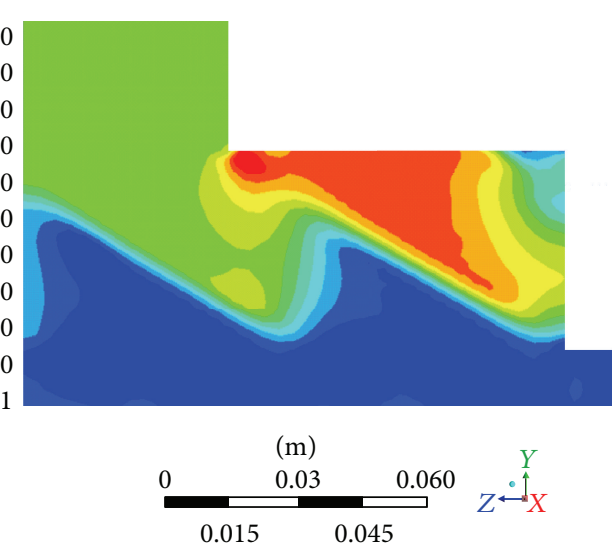

(b)

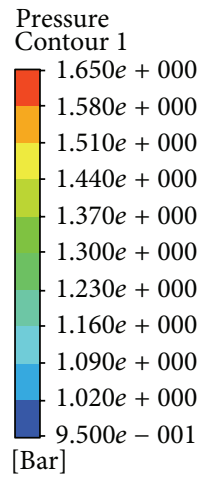

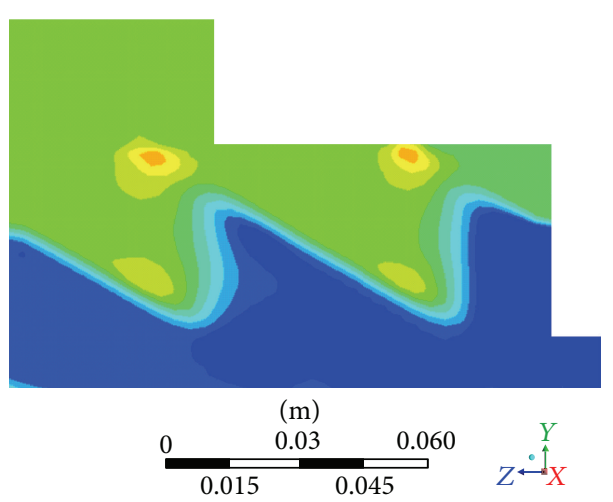

(c)

Figure 6: (a) Rotor during the compression process. (b) Rotor at the compression end stage position. (c) Rotor position after the exhaust stage.

reaches the exhaust orifice), and (5) the stage after exhaust, as shown in Figure 7.

It can be seen from Figure 7 that before the rotor makes contact with the slot, the compression chamber pressure is about $0.13 \mathrm{MPa}$, which is slightly lower than the back pressure of $0.1394 \mathrm{MPa}$. At this time, the twin-screw engine-driven supercharger is in an undercompressed state, and when the rotor makes full contact with the slot, the compression chamber pressure soon reaches the back pressure and does not significantly change until the rotor reaches the exhaust position.

To further analyze the effect of pressure pulsation on the noise value in the simulation process, two control points were set up in the flow field at the compression end positions of the male and female rotors near the exhaust orifice or the slot. The corresponding pressure fluctuation is shown in Figure 8.

Before optimization, the compression chamber is overcompressed, with a pulsation peak of about $0.162 \mathrm{MPa}$, and, after optimization, the compression chamber is undercompressed, with a pulsation peak of about $0.118 \mathrm{MPa}$. According to the SPL calculation formula,

$$
L_{p}=10 \lg \frac{p^{2}}{p_{0}^{2}}(\mathrm{~dB}),
$$

where $p_{0}$ is the reference sound pressure, defined as $2 \times$ $10^{-5} \mathrm{~Pa}, L_{p}$ is the sound pressure level value, and $p$ is taken as the difference between the pulse peak value and the back pressure of $0.135 \mathrm{MPa}$; the calculation results are listed in Table 1.

It can be seen from the calculation results that, after lowering the compression end pressure, the compression state changes from an overcompressed state to an undercompressed state and the compression end pressure is closer to the back pressure (differing by about $0.01 \mathrm{MPa}$ ); therefore, the noise value of the new model is about $4 \mathrm{~dB}$ lower than that of the old model.

\section{Experimental Program and Analysis of Results}

Experiments of noise signal acquisition were carried out before and after improvement of the twin-screw supercharger. The experimental setup is built in the engine laboratory. The engine drives the twin-screw machinery through the belt pulley. The CoCo- 80 signal analyzer probe holder was placed close to the engine, and the signal acquisition time was set to 8 seconds. The experimental apparatus is shown in Figure 9. 

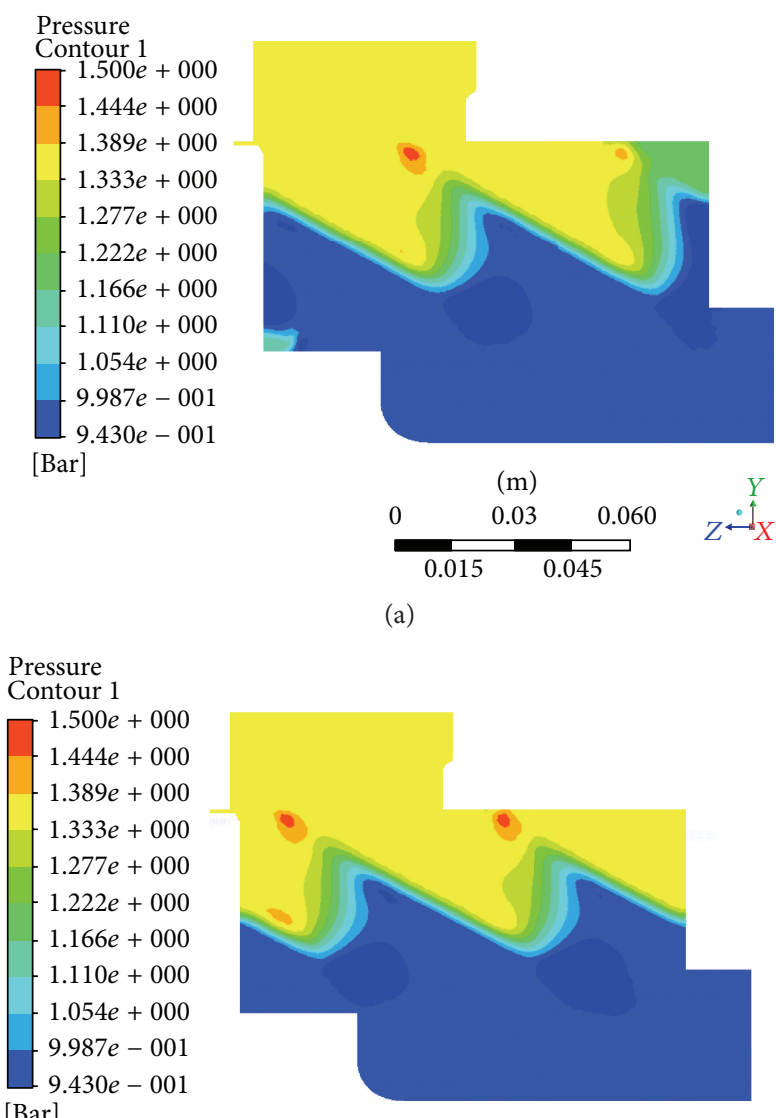

(a)
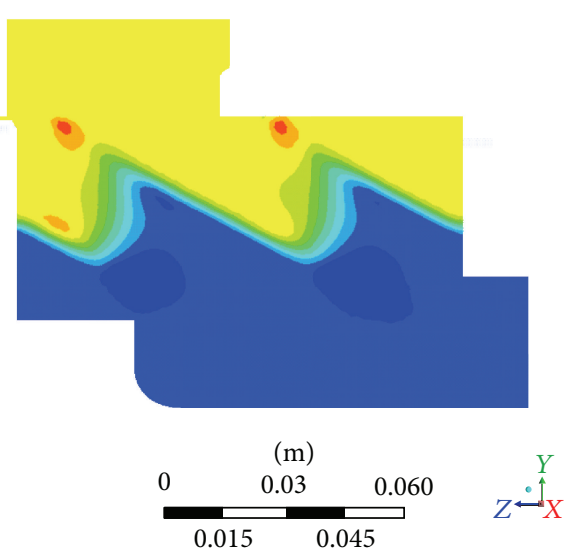

(c)
Pressure

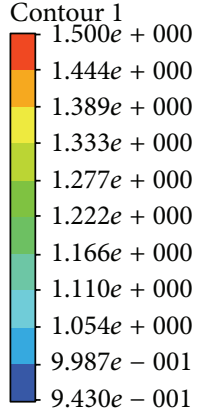

[Bar]
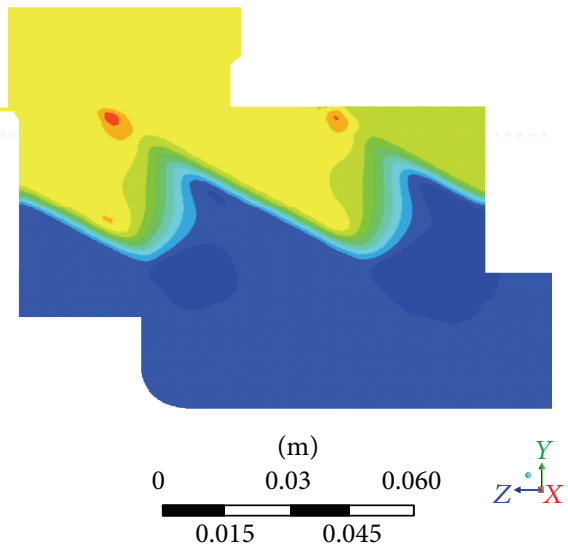

(b)

Pressure

$1.500 e+000$

$1.444 e+000$

$1.389 e+000$

$1.333 e+000$

$1.277 e+000$

$1.222 e+000$

$1.166 e+000$

$1.110 e+000$

$1.054 e+000$

$9.987 e-001$

$9.430 e-001$

[Bar]
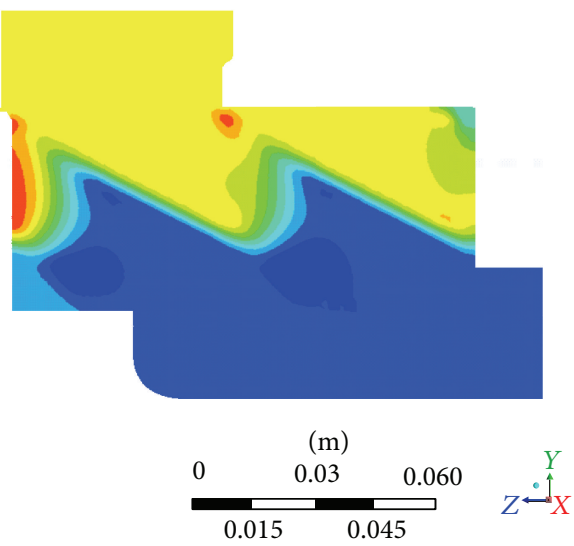

(d)

Pressure

Contour 1
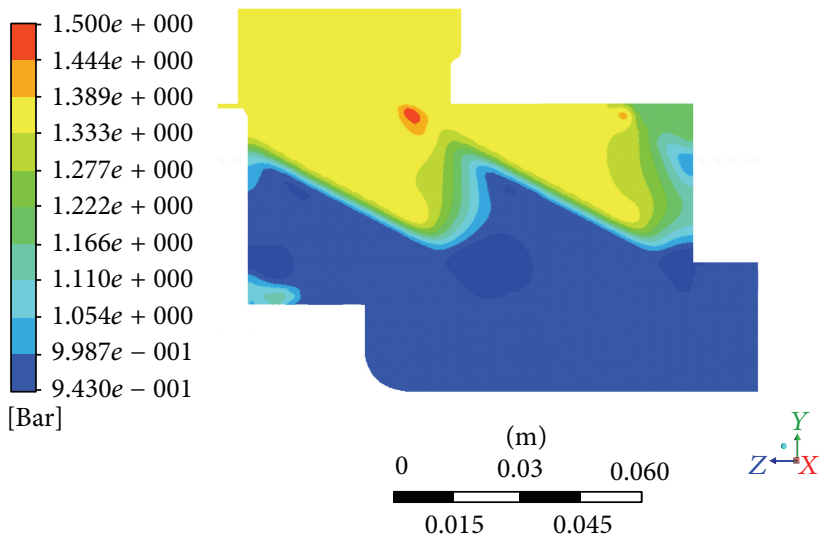

(e)

Figure 7: (a) Rotor before contact with the slot. (b) Rotor at the beginning of contact with the slot. (c) Rotor during contact with the slot. (d) Rotor at the end of contact with the slot. (e) Rotor after the exhaust stage.

During the experiment, as the speed ratio between the engine and the supercharger was $1: 3$, when the engine speed changed from $1200 \mathrm{r} / \mathrm{min}$ to $4000 \mathrm{r} / \mathrm{min}$, the appropriate supercharger speed range was 3600 to $12000 \mathrm{r} / \mathrm{min}$. With the engine speed changed, the noise signal was recorded when the speed was stable. The same signal acquisition was conducted of the superchargers before and after the improvement, respectively, and a spectral analysis of the data 


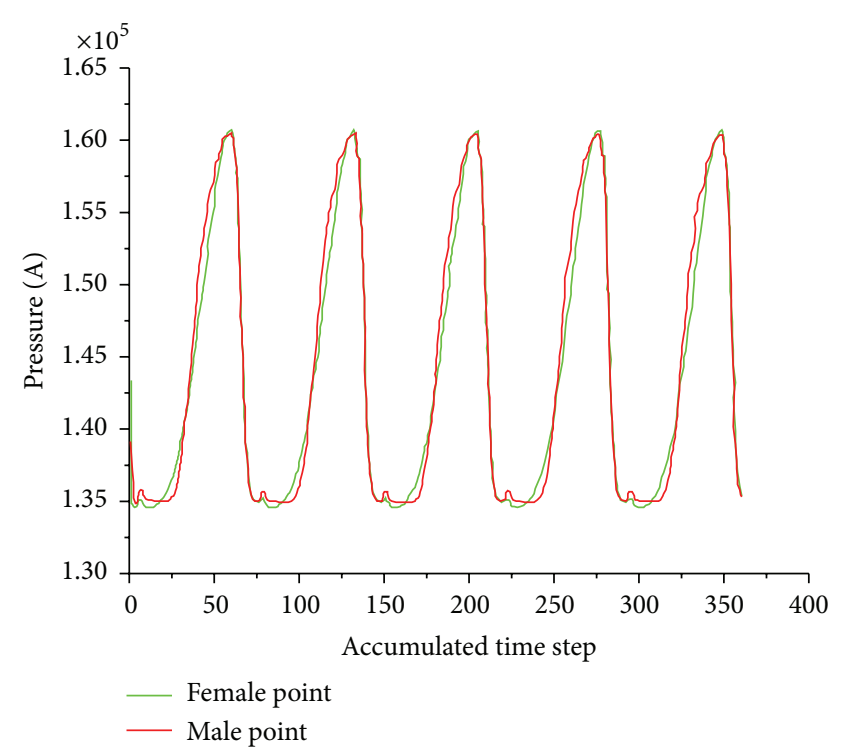

(a) Old model

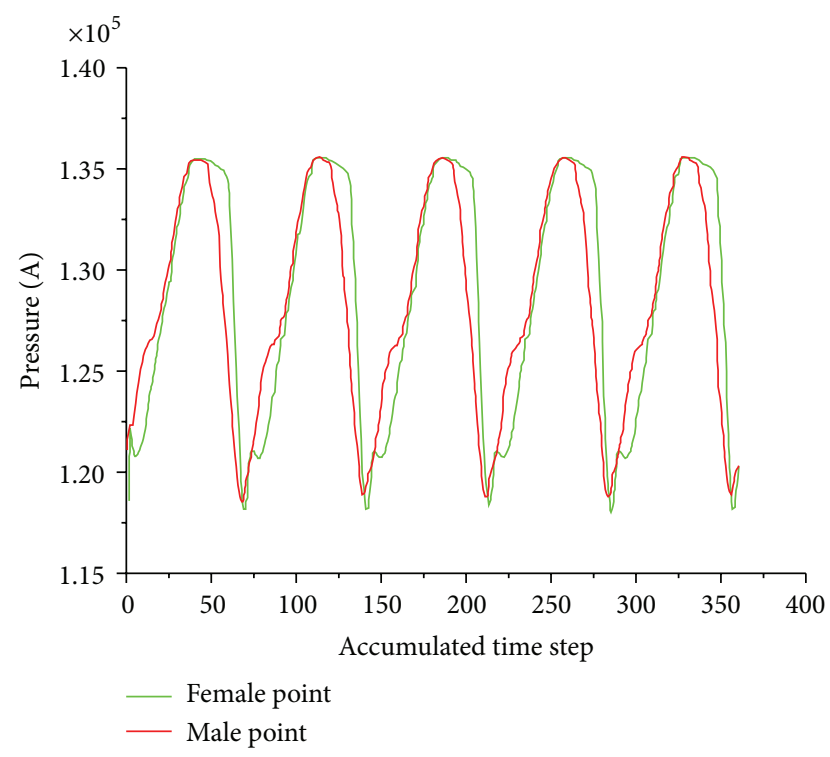

(b) New model

FIGURE 8: Pressure fluctuation at the monitoring point.

TABLE 1: Calculation of the pressure pulsation peak SPL value.

\begin{tabular}{lccccc}
\hline & $\begin{array}{c}\text { Reference sound } \\
\text { pressure }(\mathrm{Pa})\end{array}$ & $\begin{array}{c}\text { Background } \\
\text { pressure }(\mathrm{Pa})\end{array}$ & Peak pressure $(\mathrm{Pa})$ & $\begin{array}{c}\text { Average fluctuation } \\
\text { pressure }(\mathrm{Pa})\end{array}$ & $\begin{array}{c}\text { Noise calculation } \\
(\mathrm{dB})\end{array}$ \\
\hline Before optimization & 0.00002 & 135000 & 162000 & 27000 & 182.6066754 \\
After optimization & 0.00002 & 135000 & 118000 & 17000 & 178.5883785 \\
\hline
\end{tabular}

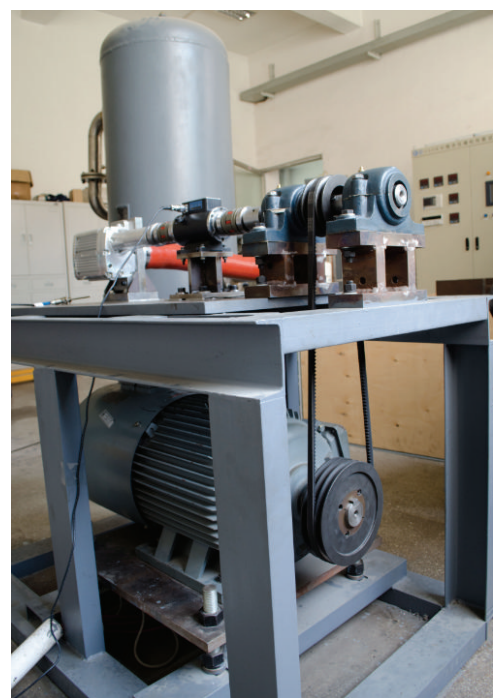

FIGURE 9: Twin-screw supercharger noise signal acquisition laboratory bench.

was performed. The two spectrograms at the same rotating speed have been compared to determine the noise reduction.

To compare and analyze the noise situations of the two superchargers before and after improvement, the spectrograms at five different speeds were selected for comparison: $3600 \mathrm{r} / \mathrm{min}, 6600 \mathrm{r} / \mathrm{min}, 8400 \mathrm{r} / \mathrm{min}, 10,200 \mathrm{r} / \mathrm{min}$, and
$12,000 \mathrm{r} / \mathrm{min}$. From the corresponding spectral data, the changes in the noise of the original model and the improved model with changes in speed are shown in Table 2.

It can be seen from the data in Table 2 that the main noise frequencies of the twin-screw engine-driven superchargers before and after the improvement were around $1000 \mathrm{~Hz}$. With an increase in speed, both the basic frequency sound pressure level and the A-weighting total sound pressure value gradually increased, and those of the improved model averaged about $5 \mathrm{~dB}$ lower than those of the original model at the same speed, thereby proving that a reduction in the exhaust pressure can effectively reduce noise of twin-screw engine-driven superchargers.

\section{Conclusions}

Transient numerical simulations of the flow fields of twinscrew engine-driven superchargers were conducted with CFD software, and the pressure field was analyzed during rotor operation. On this basis, an optimization program for the supercharger was proposed: to expand the supercharger's exhaust orifice and create a slot on the exhaust orifice along the direction of helical normal line of the rotor to reduce the compression end pressure and improve the exhaust flow channel, thereby reducing the possibility of generating a shock wave during the exhaust process and reducing the source of noise. 
TABLE 2: Spectrogram data summary sheet.

\begin{tabular}{|c|c|c|c|c|c|c|}
\hline \multirow{2}{*}{$\begin{array}{l}\text { Supercharger } \\
\text { speed (r/min) }\end{array}$} & \multicolumn{2}{|c|}{ Signal basic frequency $(\mathrm{Hz})$} & \multicolumn{2}{|c|}{ Basic frequency sound pressure level (dB) } & \multicolumn{2}{|c|}{ A-weighting total sound pressure level $(\mathrm{dB})$} \\
\hline & $\begin{array}{c}\text { Original } \\
\text { model }\end{array}$ & $\begin{array}{l}\text { Improved } \\
\text { model }\end{array}$ & Original model & Improved model & Original model & Improved model \\
\hline 3600 & 1258.9 & 1000 & 88.56 & 79.39 & 95 & 88 \\
\hline 6600 & 1000 & 1000 & 94 & 89.5 & 98.5 & 94 \\
\hline 8400 & 1258.9 & 1258.9 & 100.9 & 91 & 103 & 97 \\
\hline 10,200 & 794.3 & 2511.8 & 101.4 & 92 & 104.5 & 99.8 \\
\hline 12,000 & 1000 & 794.3 & 102.5 & 98.2 & 106 & 102 \\
\hline
\end{tabular}

The following conclusions were drawn:

(1) Exhaust noise is a major noise source of twin-screw engine-driven superchargers. Overcompression can easily produce shock waves during the exhaust process and generate intense noise; therefore, the pressure difference at the exhaust moment should be minimized.

(2) After the improvement, the noise produced by the twin-screw supercharger was significantly reduced, and the exhaust process of undercompression verified the correctness of the theory of gas pulsation. In addition, it also proved that the noise produced by the expansion wave is less than that of the compression wave, providing a reference for noise study.

(3) The experimental results show that the noise level can be effectively reduced by an average of about $5 \mathrm{~dB}(\mathrm{~A})$ by enlarging the exhaust orifice and improving the exhaust gas channel; however, because of significant changes in the supercharger working conditions, it is necessary to propose more ways of eliminating the generation of shock waves to reduce the noise over a wide range (e.g., the pulsation trap proposed by Huang $[17,18])$.

\section{Nomenclature}

$\begin{array}{ll}t: & \text { Time }[\mathrm{s}] \\ \rho: & \text { Density }\left[\mathrm{kg} / \mathrm{m}^{3}\right] \\ u, v, w: & \text { Cartesian coordinate velocity }[\mathrm{m} / \mathrm{s}] \\ p: & \text { The pressure acting on the fluid }[\mathrm{MPa}] \\ \tau: & \text { The viscous stress }[\mathrm{Pa} \cdot \mathrm{s}] \\ c_{p}: & \text { Specific heat capacity }[\mathrm{J} /(\mathrm{kg} \cdot \mathrm{K})] \\ k: & \text { Thermal conductivity }[\mathrm{W} /(\mathrm{m} \cdot \mathrm{K})] \\ S: & \text { Viscous dissipation. }\end{array}$

\section{Competing Interests}

The authors declare that they have no competing interests.

\section{References}

[1] K. Koai and W. Soedel, "Gas pulsations in screw compressors. Part I: determination of port flow and interpretation of periodic volume source," in Proceedings of the International Compressor
Engineering Conference, Paper 726, pp. 368-377, Purdue University, West Lafayette, Ind, USA, 1990.

[2] K. L. Koai and W. Soedel, "Gas pulsations in twin screw compressors. Part II: dynamics of discharge system and its interaction with port flow," in Proceedings of the International Compressor Engineering Conference, Purdue, 1990.

[3] H. Wu, Z. Xing, X. Peng, and P. Shu, "Simulation of discharge pressure pulsation within twin screw compressors," Proceedings of the Institution of Mechanical Engineers, Part A: Journal of Power and Energy, vol. 218, no. 4, pp. 257-264, 2004.

[4] P. X. Huang, S. Yonkers, D. Hokey, and D. Olenick, "Screw pulsation generation and control: a shock tube mechanism," in Proceedings of the 8th International Conference on Compressors and Their Systems, pp. 113-128, London, UK, September 2013.

[5] E. Mujic, A. Kovacevic, N. Stosic, and I. K. Smith, "The influence of port shape on gas pulsations in a screw compressor dischange chamber," Proceedings of the Institution of Mechanical Engineers, Part E, vol. 222, no. 4, pp. 211-223, 2008.

[6] P. Mahendra and M. G. Olsen, "Unsteady velocity field measurements at the outlet of an automotive supercharger using particle image velocimetry (PIV)," Experimental Thermal and Fluid Science, vol. 33, no. 3, pp. 405-423, 2009.

[7] D. I. Blekhman, J. C. Mollendorf, J. D. Felske, and J. Lordi, "Multi-control-volume analysis of the compression process in a high-temperature root's type compressor," International Journal of Rotating Machinery, vol. 10, no. 1, pp. 45-53, 2004.

[8] A. M. Joshi, D. I. Blekhman, J. D. Felske, J. A. Lordi, and J. C. Mollendorf, "Clearance analysis and leakage flow CFD model of a two-lobe multi-recompression heater," International Journal of Rotating Machinery, vol. 2006, Article ID 79084, 10 pages, 2006.

[9] H. Li, X. Zhang, X. Zhang, S. Yang, and F. Xu, "Pressure pulsation signal analysis for centrifugal compressor blade crack determination," Mathematical Problems in Engineering, vol. 2014, Article ID 862065, 15 pages, 2014.

[10] P. Cyklis, "A CFD based identification method of the transmittances for the pulsating gas installation element," in Proceedings of the Purdue Compressor Technology Conference, pp. C17215C17216, 2002.

[11] D. I. Blekhman, "Multi-control-volume analysis of the compression process in a high-temperature Root's type compressor," International Journal of Rotating Machinery, vol. 10, pp. 45-53, 2004.

[12] A. Kovacevic, "Boundary adaptation in grid generation for CFD analysis of screw compressors," International Journal for Numerical Methods in Engineering, vol. 64, no. 3, pp. 401-426, 2005.

[13] A. Kovacevic, N. Stosic, and E. Mujic, "CFD integrated design of screw compressors[J]," Engineering Applications of Computational Fluid Mechanics, vol. 1, no. 2, pp. 96-108, 2007. 
[14] Z. F. Huang and Z. X. Liu, "Numerical study of a positive displacement blower," Proceedings of the Institution of Mechanical Engineers, Part C: Journal of Mechanical Engineering Science, vol. 223, no. 10, pp. 2309-2316, 2009.

[15] H. Matsubara, K. Miyashita, Y. Iguchi, S. Tanaka, K. Akiyama, and F. Nakamura, "Superior charging technology by screw supercharger and high technology turbocharger for automotive use," SAE Technical Paper 890455, SAE International, 1989.

[16] D. X. Fu and Y. W. Ma, Computational Fluid Dynamics, Higher Education Press, Beijing, China, 2002.

[17] P. X. Huang, "Gas pulsations: a shock tube mechanism," in Proceedings of the 21st International Compressor Engineering Conference, Paper 2092, pp. 1-10, Purdue University, West Lafayette, Ind, USA, July 2012.

[18] P. X. Huang, "Under compression (over expansion)-an isochoric or adiabatic process," in Proceedings of the 21st International Compressor Engineering Conference at Purdue, vol. 1305, no. 8, July 2012. 


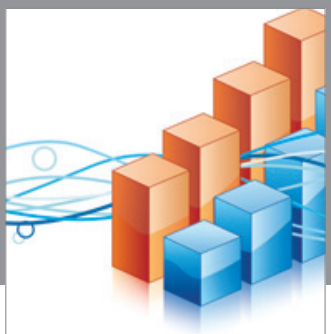

Advances in

Operations Research

vatem alat4

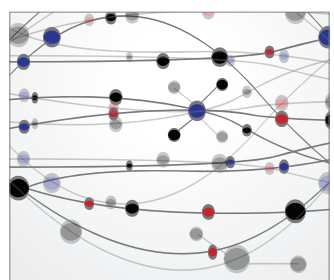

\section{The Scientific} World Journal
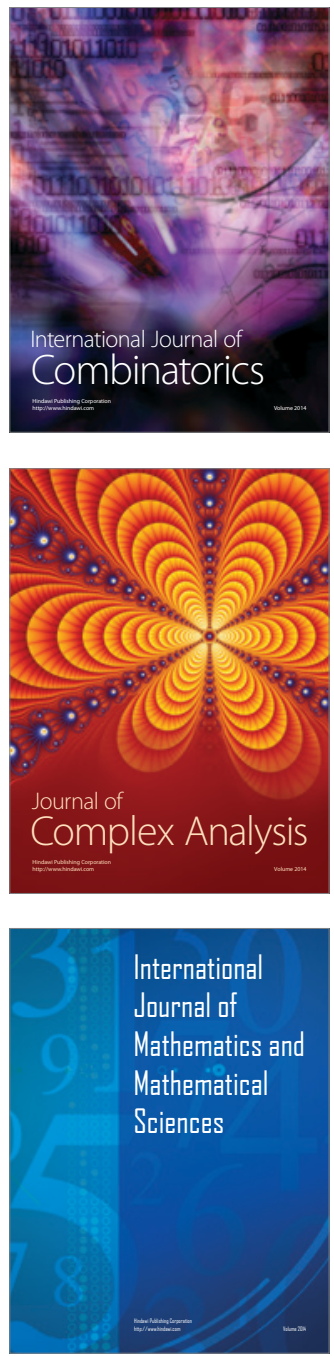
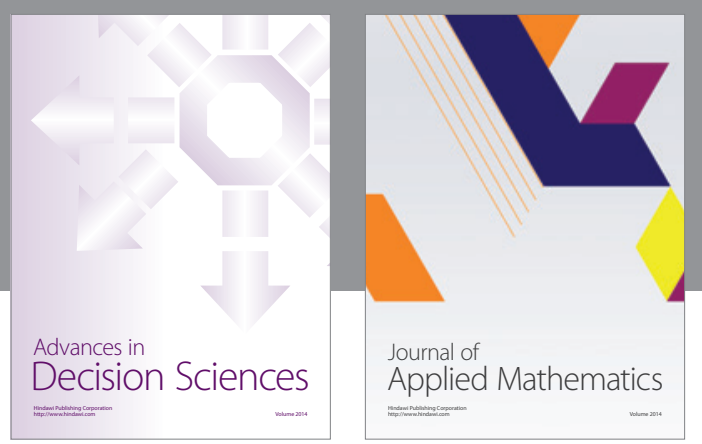

Algebra

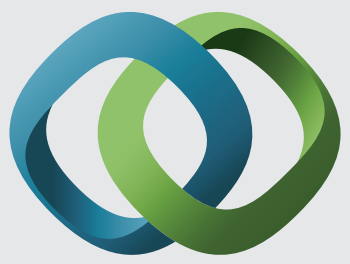

\section{Hindawi}

Submit your manuscripts at

http://www.hindawi.com
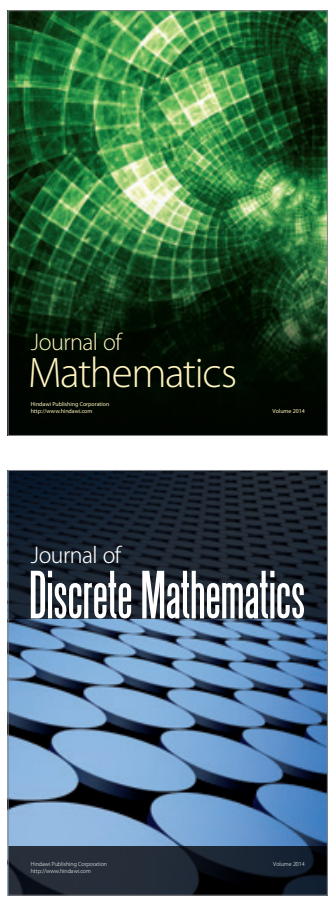

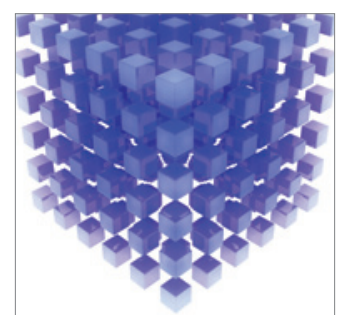

Mathematical Problems in Engineering
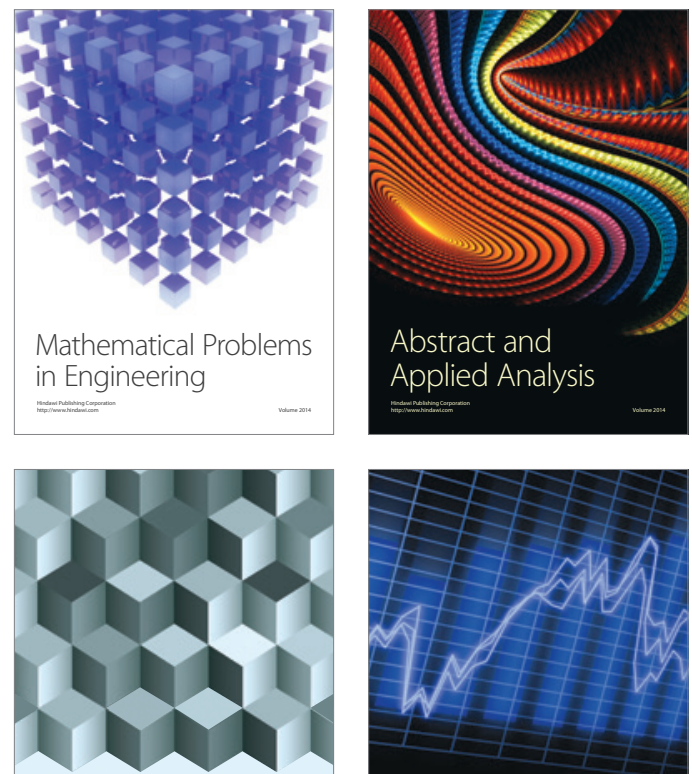

Journal of

Function Spaces

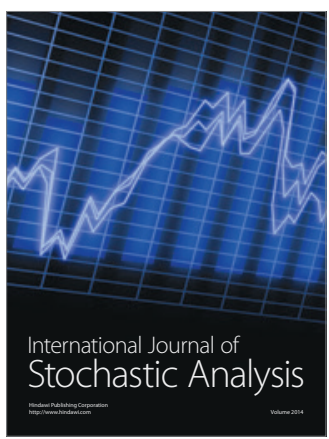

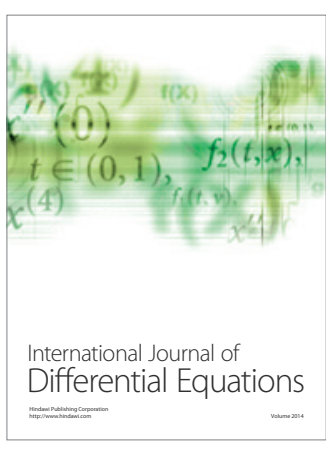
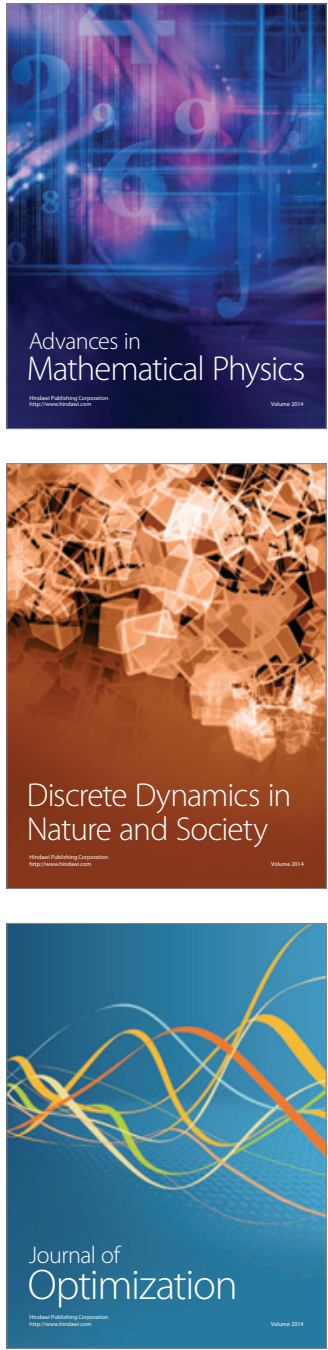